\title{
Volver al pozo: \\ de la violencia de la trata al estatus de dreamer \\ (Gén 37,12-36)
}

\author{
Back to the Well: \\ From Trafficking Violence to Dreamer Status
}

(Gen 37,12-36)

\begin{abstract}
Resumen
El análisis del relato sobre el joven José lanzado al pozo y vendido a una caravana, desde una perspectiva de trata de personas y migración de menores no acompañados, busca la posibilidad de revisitar los antecedentes traumáticos y al mismo tiempo resilientes del personaje. Conectando directamente con el entorno patriarcal que pone violencia y precio al cuerpo de un niño diferente y sobreviviente a otras violencias, este abordaje intenta ofrecer elementos interpretativos que permitan un acercamiento en clave de masculinidades las relaciones de poder entre los personajes literarios masculinos presentes en el texto, para identificar la resiliencia como posibilidad de cambio en un mundo patriarcal.
\end{abstract}

Palabras clave: Niñez, José, violencia, resiliencia, trata, masculinidades

\begin{abstract}
The analysis of the story about the young José thrown into the well and sold to a caravan, from a perspective of human trafficking and migration of unaccompanied minors, seeks the possibility of revisiting the traumatic and at the same time resilient background of the character. Connecting directly with the patriarchal environment that puts violence and a price on the body of a different child and survivor of other violence, this approach tries to offer interpretative elements that allow an approach in the key of masculinities the power relations between the male literary characters present in the text, to identify resilience as a possibility of change in a patriarchal world.
\end{abstract}

\footnotetext{
${ }^{1}$ Teólogo y biblista, Diplomado de la EBAF Jerusalén, certificado internacional en Terapia Guestalt (INTEGRO, México) y Salud Sexual y Reproductiva (Public Health Institute, California, EE. UU.). Docente, Investigador y formador en el Programa de Masculinidades del Centro Bartolomé de las Casas de Centroamérica (Correo electrónico: larryjose@gmail.com).
} 
Keywords: Childhood, Joseph, violence, trafficking, masculinities.

\section{La crisis de los niños y las niñas migrantes en "la perrera"}

Vinimos a Estados Unidos porque había gente que quería hacernos daño / Aquí en Clint siempre tengo hambre. Tengo tanta hambre que me he despertado en medio de la noche con hambre. Tengo demasiado miedo para pedir más comida a los funcionarios / No hay agua ni jabón para lavarnos las manos después de ir al baño. Mi hermana y yo nos abrazamos con una manta para que nadie pueda vernos ir al baño / Tengo cinco años. Yo soy de Honduras / Tengo siete años. Yo soy de El Salvador / Los agentes me separaron de mi papá. No he vuelto a ver a mi papá / Estaba mojado cuando llegué aquí y me metieron en la jaula sin que me dieran ropa seca. Está muy frío. Estaba temblando muy fuerte / Soy la tercera muchacha que ha tratado de cuidar a este niño de dos años. Le doy de comer y le doy agua. También cuido de otra niña chiquita. Ella me llama mamá. Tiene seis años / Aquí no hay espacio para moverse sin pasar por encima de los demás / No nos dan una colchoneta para dormir. Así que tuvimos que dormir en el suelo frío de cemento. Las luces están encendidas siempre / No podemos dormir porque cada 15 a 20 minutos, los guardias gritan algo. “iLevántense!” / Pasamos todo el día y todos los días dentro de ese cuarto. No hay actividades, solo llorar (VARJACQUES y JENSSEN, 2019).

El periódico The New York Times publicó un vídeo donde niños y niñas leen testimonios de niños y niñas que habían estado en jaulas (en inglés: $c a-$ ges) en centros de detención de la frontera sur de los Estados Unidos, en custodia después de ser abandonados capturados y etiquetados como "menores no acompañados ${ }^{2 \prime}$. Los testimonios, bien documentados y ahora accesibles ${ }^{3}$ , son una vitrina de horror de lo que pudo haber significado el tratamiento como convicto, el abandono y aislamiento de las redes familiares, la discriminación y las carencias materiales básicas para niños y niñas menores de 16 años de El Salvador, Honduras y Guatemala. Entre 2016 y 2019 más de 1,000 niños inmigrantes que llegaron a la frontera sur de Estados Unidos sin sus padres han informado haber sido abusados sexualmente mientras estaban bajo custodia del gobierno, según registros federales (GONZALES, 2019). Al leer esas líneas, se reconoce casos cercanos, se recuerda noticias de todas las noches y duele el corazón al ver esos niños en jaulas y escuchar sus

\footnotetext{
${ }^{2}$ El Departamento de Seguridad Nacional (DHS), define como 'niño no acompañado' al menor extranjero que no ha cumplido los 18 años de edad, que no tiene un padre o tutor legal en Estados Unidos y que tampoco cuenta en el país con una persona que le proporcione cuidado y custodia física.

${ }^{3}$ El National Center for Youth Law ha abierto un repositorio (en inglés) de documentos adjuntos de presentación de una orden de restricción temporal. Disponible en:

https://youthlaw.org/troaccompanyingdocuments/ Visitado el: 25 nov. 2020
} 
voces grabadas llamando a sus parientes mientras se ríen los agentes que custodian "la perrera".

En los años recientes, miles de niñas y niños migrantes centroamericanos han sido detenidos en la frontera sur de los Estados Unidos. Estos niños que viajan sin la compañía de un adulto, desde Centroamérica, han intentado llegar a Estados Unidos durante los últimos años, arriesgándose a que los detenga la policía, al maltrato de los traficantes de personas y a las terribles condiciones de frío, calor, hambre y distancias que encuentran en el largo trayecto. Desde 2014, cuando se supo de la llamada "crisis de los niños migrantes", cerca de 290.000 menores provenientes de los países centroamericanos fueron detenidos por las autoridades estadounidenses a lo largo de la frontera con México (SHOICHET, 2021). Durante gran parte de 2020 y como resultado de una orden de salud pública relacionada con la Covid-19, conocida como Título 42, todos los migrantes indocumentados son expulsados a México, excepto los niños no acompañados que cruzaban la frontera. Según las estimaciones que maneja el Departamento de Seguridad Nacional, unos 117,000 menores migrantes que viajan solos estarán cruzando la frontera en 2021. Grandes oleadas récord de niños, niñas y familias han aparecido de manera constante con la llegada de la Covid-19 en 2020.

Aunque muchos logran llegar a su destino, a algunos los secuestran los mismos coyotes con quienes sus familias se endeudaron para que los pasaran de contrabando a Estados Unidos; otros perdieron extremidades durante el viaje o fueron vendidos con fines de explotación sexual. Otros pudieron regresar.

Millones de niñas y niños migrantes y refugiados hoy sufren por los desplazamientos geopolíticos y lingüístico-culturales que se ven obligados a enfrentar por motivos diversos (empobrecimiento, violencia, discriminación, abuso, etc.) y sobre los que carecen de control alguno, lo que constituye una herida significativa, a veces letal para ellas y ellos y, de diversas maneras, para las varias comunidades involucradas. Se trata de un negocio estimado en unos 7,000 millones de dólares sólo en los Estados Unidos, que enfoca poco en el microcosmos de las personas concretas, esas niñas y niños que trascienden la etiqueta jurídica y de medición de "menores no acompañados". ${ }^{4}$

Muchas de las historias de migración tienen final feliz pero siempre involucran, en mayor o menor medida, un grado de trauma porque en el desplazamiento físico y simbólico se hace inevitable la pérdida y la distancia. Las profundidades e implicancias de dicho trauma no solo difieren de

\footnotetext{
${ }^{4}$ Mercedes Jiménez (2014) destaca que diversos autores han criticado el uso de este término que despoja a los menores de sus referencias, pertenencias y contextos, proponiendo otras formas de nombrarlos: p.e. "menores migrantes sin un referente adulto en el país receptor". Aquí usamos la etiqueta como estrategia de visibilidad, pero denunciamos que aplicada a la situación creciente de menores que migran, deja ver un adulto centrismo epistemológico y metodológico que devela la visión desde el poder de las sociedades receptoras.
} 
un caso a otro, sino que representan un amplísimo espectro que depende de una variedad compleja de factores. Uno de ellos, poco atendido en la narrativa judicial y política, es la capacidad del sujeto de resistir y superar la adversidad, es decir, la resiliencia, entendida como el proceso de adaptarse bien frente a la adversidad, el trauma, la tragedia, las amenazas o fuentes importantes de estrés (APA, 2012). Si bien la resiliencia implica "recuperar$\mathrm{se}^{\prime \prime}$ de las experiencias difíciles, también puede implicar un profundo crecimiento personal que no olvida o borra las experiencias difíciles y ayuda a construir un proyecto de vida. Sin embargo, ¿Qué pasa, en los casos de los menores de edad expuestos a las presiones, incidencias, abusos, estancias en jaulas, cuya vulnerabilización es notoria, tanto como sujetos de derecho como en cuanto a personas con potencial proyecto de vida?

En concreto, a nivel global, muchos niños y adolescentes viajan solos, llevando a cuestas un peligro considerablemente mayor que para cualquier adulto, aunque las razones para el viaje sean básicamente las mismas (busca de refugio, reunificación familiar o el sueño y promesa de una vida mejor). De la cifra escalofriante de 60 millones de niños y niñas que han migrado a otra nación o fueron desplazados por la fuerza dentro de sus propios países en 2020, UNICEF (2020), reportó que nueve de cada diez niños no acompañados que buscaban asilo eran varones. Los niños se enfrentan a la deportación. Otros, si tienen suerte, a una reunificación con familiares que apenas conocen y pueden causar todavía más trauma, o a ser cobijados hasta la mayoría de edad por el sistema de resguardo temporario, ya sea bajo la modalidad de "padres de crianza" (foster parenting) o del "hogar de abrigo" (shelter), para luego padecer, etiquetados por su origen y abrumados por la exclusión, el limbo de la detención carcelaria. Los más más resilientes, han logrado perseverar, estudiar y ser dreamers ${ }^{5}$ (soñadores), estando dentro, pero sin ser parte, con favores y beneficios, pero sin ciudadanía o residencia permanente, vistos con sospecha como dijo el presidente Trump: "Los he visto y he mirado a sus ojos [...], y he dicho: 'Este es un futuro pandillero de la MS-13'"' (SULLIVAN, 2019).

\section{José, hijo de Raquel y Jacob}

Como bien dice Yvone Gebara en la introducción de este número: "debemos organizarnos teniendo delante de nuestros ojos las heridas reales de las personas que más sangran y de ellas tratar de ver los posibles pasos para aliviar los dolores y las pesadas cargas que llevan", vamos a leer un

\footnotetext{
${ }^{5}$ Los Dreamers son aproximadamente 2.1 millones de indocumentados que llegaron a Estados Unidos siendo niños. Aproximadamente 800 mil Dreamers se han beneficiado de la acción diferida (DACA) ordenada el 15 de junio de 2012 por el presidente Obama. El término dreamer nació con el proyecto de ley DREAM Act, de 2001 (Ley de fomento para el progreso, alivio y educación para menores extranjeros), que ofrecía un estatus legal a los inmigrantes, a cambio de asistir a la universidad o unirse al ejército.
} 
tramo de la historia de José, hijo de Raquel y Jacob, que se encuentra inserta en lo que conocemos como el ciclo de José (Gén 37,2-50,26).

José es un personaje muy conocido y evocado en la memoria popular, tanto por sus reveladores sueños desde niño como por el confuso incidente en la habitación de la esposa de Potifar, eunuco de faraón, cuando ya vivía en Egipto, situación que hemos abordado antes desde la perspectiva de las masculinidades profeministas (MADRIGAL, 2007).

En la composición de este personaje bíblico se puede percibir que el tamaño, la evidente continuidad de la trama a lo largo de los capítulos, la presentación del protagonista con contornos bien definidos, la ausencia de teofanías o discursos divinos evidencian una evolución en el arte de narrar que contrasta con otras historias patriarcales en la descripción de los personajes, en la atención a lo emocional y en la peculiar presencia de Dios vista por los protagonistas a través de los acontecimientos. Cualquier intento de reconstruir el proceso de redacción del ciclo de José, bastante estudiado y con abundante literatura ${ }^{6}$ resulta muy complejo, pero tras los rasgos con los que se presenta al protagonista parecen entretejerse desde dos tradiciones. Una de ellas dibujaría a José, instalado en Egipto, muy asimilado culturalmente, modelo de judío bien integrado y subrayando su estrecha relación con los extranjeros y sus grandes cualidades como administrador, un sueño cumplido. La otra tradición seria más ambigua y pondría el acento en la relación de José con sus hermanos, un caso fallido. Las dos son muy antiguas e independientes durante mucho tiempo y originadas en espacios distintos. La primera, con clara influencia de algunos cuentos egipcios e incluso con Asiria, con posibles influencias de la leyenda del rey Esarhardon (FRAHM, 2016). La segunda parece estar más en línea con las historias patriarcales en las que Israel reflexiona sobre su origen. La unión de ambas tradiciones explicaría tanto la sutil fractura interna en el relato, como la distancia con su contexto en el Genesis.

Es innegable la importancia que la época postexílica tiene para la historia de nuestro texto, probablemente ubicando su redacción final no más tarde del siglo $\mathrm{V}$ aEC. Este momento histórico marcado por el regreso desde Babilonia se caracterizó por las tensiones reabiertas dentro del pueblo elegido, la búsqueda de consensos, la reflexión sobre los propios orígenes y la intensa presencia de elementos extraños a la propia cultura. Estos rasgos encajan bien con el relato de José y su modo de presentar las costumbres extranjeras o las referencias al Norte y al Sur de Israel, por lo que puede

\footnotetext{
${ }^{6}$ Gerhard Von Rad ofrece una rápida mirada panorámica a estas peculiaridades del ciclo de José en: La acción de Dios en Israel. Ensayos sobre el Testamento. Madrid: Trotta, 1996, pp. 23-25. A mayor especificidad: JARSCHEL, Haidi. Vientre, casa, tierra: espacios de la historiografía sexuada. Génesis 25-36. En: Pentateuco. RIBLA 23, 1996 pp. 52-63; REIMER, Haroldo. La necesidad de la monarquía para salvar al pueblo. Apuntamientos sobre la historia de José (Génesis 37-50). En: Pentateuco, RIBLA 23, 1996, pp. 64-74.
} 
aceptarse que la redacción final es de esta época (FINKELSTEIN, 2001, p. 53). La interpretación de la presencia judía en Egipto como algo querido por Dios contrasta con el modo en que esto se vive en otros relatos patriarcales (cf. Gn 12,10-20; 26,1-2). Lo que sugiere que es en ese lugar donde podría haberse culminado la redacción final.

Acerquémonos al texto en cuestión, que hemos colocado íntegro para facilitar su lectura?.

\section{De los menores, el favorito de la familia}

${ }^{12}$ Fueron sus hermanos a apacentar las ovejas de su padre en Siquén, ${ }^{13} \mathrm{y}$ dijo Israel a José: "Mira, tus hermanos están pastoreando en Siquém. Ve de mi parte adonde ellos". Dijo: "Estoy listo". ${ }^{14}$ Le dijo: "Anda, vete a ver si tus hermanos siguen sin novedad, y lo mismo el ganado, y tráeme noticias". Lo envió, pues, desde el valle de Hebrón, y José fue a Siquém. ${ }^{15}$ Se encontró con él un hombre mientras iba desorientado por el campo. El hombre le preguntó: “Qué buscas?” ${ }^{16}$ Contestó: “Estoy buscando a mis hermanos. Indícame, por favor, dónde están pastoreando". ${ }^{17}$ El hombre le dijo: "Partieron de aquí, pues yo les oí decir: 'Vamos a Dotán"'. José fue detrás de sus hermanos y los encontró en Dotán.

José, al que hemos identificado ya como hijo de la segunda esposa de Jacob, es el mayor de sus dos últimos hijos. Un poco antes de este episodio, siempre dentro del ciclo, se nos reportan datos de mucha relevancia para ubicar una masculinidad diferente de José. De él se dice que es de "bella presencia y de buen ver" y son exactamente las mismas palabras que antes se han utilizado para describir a su madre, Raquel (Gén 29,17). Tiene 17 años y en el contexto narrativo ya es considerado adulto. También se nos relata (Gén 37,3) que era el favorito de su padre y que éste le había distinguido regalándole una "túnica de mangas largas" (kettonet passim), cuyo uso encontramos mencionado solamente para Tamar (2Sam 13,18), princesa real. Aunque se indica que acompañaba a sus hermanos pastando a las ovejas (más bien parecía que los pastoreaba, por los reportes que daba después a su padre sobre ellos), José no trabajaba en el campo como se ve en la alusión a la túnica larga, incómoda, y era retenido por su padre Jacob en la casa. Se nos reporta que, por esa preferencia, tanto como por relatar sus sueños, José llegó a ser aborrecido por sus hermanos, enfatizando el odio (mencionado tres veces, אֵָָּ, sane) y la envidia de ellos (Gén 37,4-5.8.11).

Según el relato, José emprendería un viaje no corto, uno o dos días, porque Jacob y su familia vivían cerca de Hebrón, que estaba situada a unos 40-50 kilómetros de Siquém, a una distancia similar, pero en dirección al

\footnotetext{
7 Todos los textos de Nueva Biblia de Jerusalén, 5a edición, Bilbao: Desclée de Brouwer, 2018, a menos que se indique lo contrario.

8 "werāhēēl hāyatâ yefat-tō'ar wîfat mara'eh"
} 
norte. Así que los hermanos de José estaban apacentando las ovejas bastante lejos de la casa, cuestión más o menos rutinaria y conocida por los hermanos mayores, puesto que las tierras de pastoreo abarcaban la totalidad de aquella extensa zona hasta Siquén, además escenario de conflicto después del rapto y violación de Dina (Gén 34,1-31), y que había quedado como prenda de guerra de Jacob.

Cuando José llega a Siquém, no encuentra a sus hermanos por ninguna parte. El texto menciona a un hombre (ish) No sabemos quién es este hombre misterioso, pero inicia la conversación. José explica el encargo de su padre (que también podríamos traducir como "Ve la paz (שלְin, shalom) de tus hermanos y la paz (שלְĭ, shalom) de las ovejas, y tráeme la respuesta" (v. 14) y pide ayuda para encontrar a sus hermanos. El hombre lo manda a Dotán, cada vez más lejos (unos 20 kilómetros más). La migración de José ya ha iniciado, aun sin saberlo.

El lugar, Dotán, está tradicionalmente asociado a Tell Dothan (Ramot Korazim, Galilea), en el lado sur de la llanura de Jezreel, a unas 12 millas al norte de Samaria. De hecho, el lugar tradicional es conocido como el "pozo de José" (en árabe, Jubb Yusuf).

Dotán se ubicaba en la línea del tráfico ordinario de las caravanas de tratantes, comerciantes y migrantes entre Siria y Mesopotamia con Egipto. El comercio lo realizaban mercaderes que viajaban en compañías, con camellos y caravanas, completamente amueblados y equipados tanto para la defensa como para la marcha. Parece que el lugar contaba con pastos y agua, prestos como estación de recarga.

\section{El pozo, cárcel y trauma}

${ }^{18}$ Ellos lo vieron de lejos y, antes que se les acercara, conspiraron contra él para matarlo, ${ }^{19}$ y se decían mutuamente: "Por ahí viene el soñador. ${ }^{20}$ Vamos a matarlo y lo echaremos en un pozo cualquiera, y diremos que algún animal feroz lo devoró. Veremos entonces en qué paran sus sueños". ${ }^{21}$ Rubén lo oyó y pensó en librarle de sus manos. Dijo: "No atentemos contra su vida". ${ }^{22} \mathrm{Y}$ añadió: "No derraméis sangre. Echadle a ese pozo que hay en el páramo, pero no pongáis la mano sobre él". Su intención era salvarlo de sus hermanos para devolverlo a su padre. ${ }^{23}$ Entonces, cuando llegó José donde sus hermanos, éstos despojaron a José de su túnica -aquella túnica de manga larga que llevaba puesta- $-{ }^{24} \mathrm{y}$ echándole mano lo arrojaron al pozo. Aquel pozo estaba vacío, sin agua.

En estos versículos la atención ha sido colocada casi siempre en los terribles actos de los hermanos que conspiran: "vamos a matarlo", "lo echaremos a un pozo", que con razón nos recuerdan al odio reportado antes. José va con su misión y al encontrarse, "ellos le desnudan" (heb. pashat, way $\cdot y a \bar{p} \cdot \breve{s}_{\hat{\imath}} \cdot t \bar{u}$, lo que parece haber sido violento) de la túnica y "lo tomaron 
(laqach) y lo echaron (shalak) [abajo] al pozo (bowr)". De pronto, todo parece estar centrado en el pozo: el odio de sus hermanos, el mismo José, el tiempo y el porvenir.

El pozo tiene una larga y significativa tradición simbólica en las escrituras judeocristianas, como en todo el mundo antiguo. En realidad, bowr, podría ser un pozo (como lugar con una veta de agua viva para beber), una cisterna (depósito construido para almacenar agua lluvia o estacional), un hoyo profundo cavado en la tierra o esculpido entre la roca, una mazmorra (cárcel donde poner prisioneros o castigar) e incluso un sepulcro. Exteriormente, el pozo no se diferenciaba mucho de la cisterna. Aunque debe diferenciarse de otras palabras contiguas (hebr. be'ér = pozo de agua subterránea; hebr. 'ayín, fuente; de pozo cisterna hebr. bowr; pero, como existen también pozos alimentados por agua de fuentes, se utilizan a veces las expresiones be'ér y 'ayín indistintamente; así: (Gén 24). Había numerosos pozos en la llanura marítima de Filistea, donde un curso de agua subterránea se abría camino hacia el Mediterráneo. Los pozos han sido de mucha importancia en Palestina, pobre en agua, y ante todo para los nómadas, por ello tenía pozos cavados en la roca calcárea.

De un pozo que recibe agua de una fuente, se dice correctamente "pozo de agua viva" heb. be'ér mayim hayyim: (Gén 26,19), "pero cuando los siervos de Isaac cavaron en el valle, hallaron allí un pozo de aguas vivas" (Cant 4,15), "fuente de huertos, pozo de aguas vivas que corren del Líbano"; "La mujer le dijo: Señor, no tienes con qué sacarla, y el pozo es hondo. ¿De dónde, pues, tienes el agua viva?" (Jn 4,11).

En un vetusto mural que yace en el Vaticano, puede verse evidenciado el drama de la trata de un joven José, frente al pozo: los ojos de todos los participantes están puestos con énfasis en las 20 piezas de plata (según la tradición) que cambian de manos, del mismo modo que es dificil ver el proceso personal que afecta a un joven. A la derecha están los hermanos, con el más importante, probablemente Judá, recibiendo el pago mientras agarra a José. Aparte de José, solo los camellos de los ismaelitas parecen no estar interesados en la transacción que ocurre junto al pozo, ahora vacío, en el que José había sido arrojado. Se ha normalizado tanto la situación de trata en la Biblia, especialmente por la esclavitud, que fácilmente se hace invisible. Llama la atención el contexto de la trata de José, quien, llegado con un encargo de paz, buscando por largos días y distancias a sus hermanos, tratado violentamente al ser tomado, humillado al ser desnudado y presa del pánico y la confusión, termina forcejeando ante un grupo de hombres adultos que le tiran al pozo. Finalmente, si el pozo o cisterna tendría cierta profundidad, bien estaría golpeado o herido. Nos conectamos otra vez al odio a José y su peculiar masculinidad, puesto que el pozo podría ser leído irónicamente, con connotaciones contrapuestas a la escena entre hombres: por un lado, usado metafóricamente para hacer referencia a una esposa o una mujer amada "Bebe el agua de tu misma cisterna y los raudales de tu pro- 


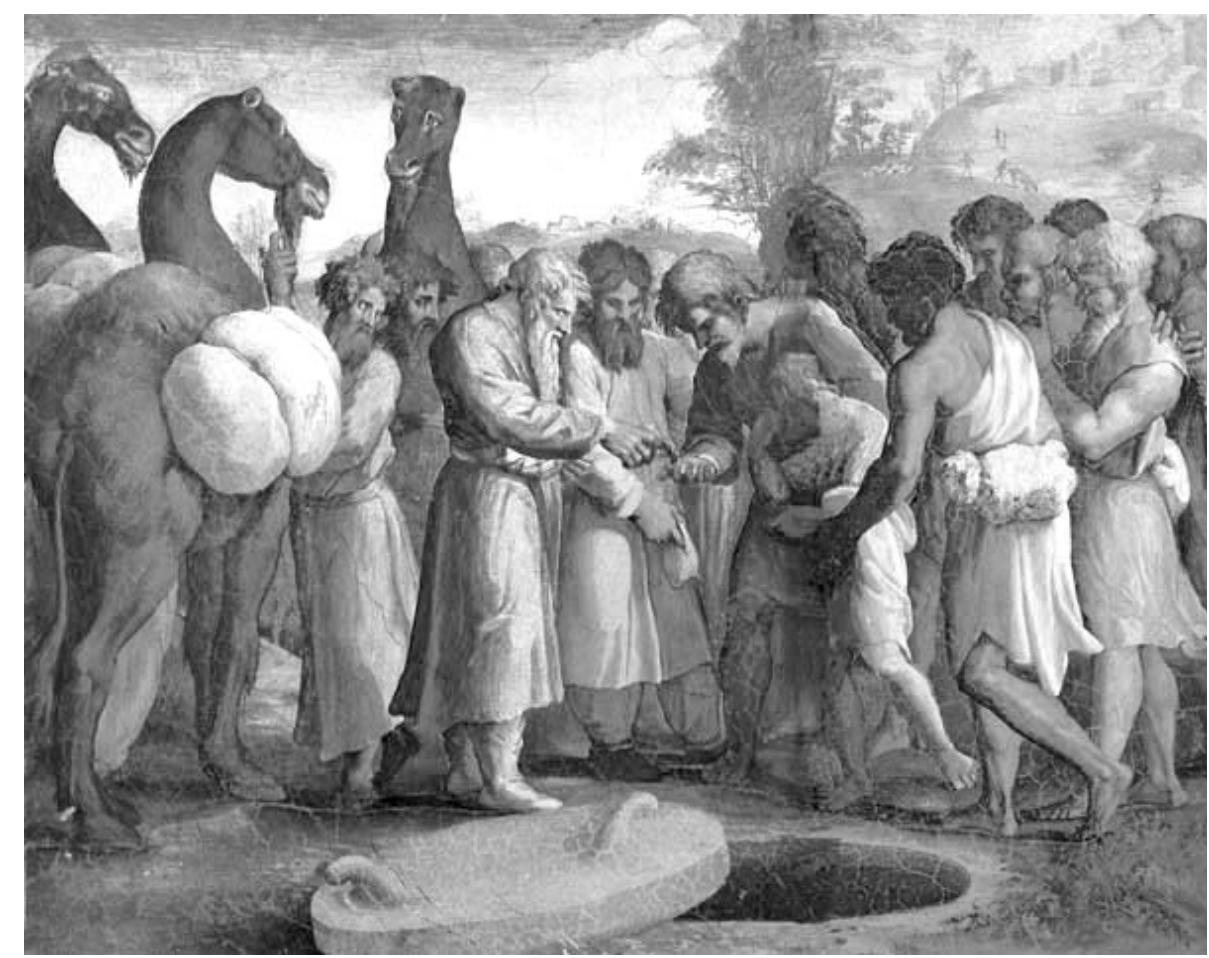

Figura 1

José es vendido por sus hermanos. Mural de Rafael Sanzio S. XVI. Museo Vaticano.

pio pozo" (Prov 5,15); "Fuente de huertos, Pozo de aguas vivas, que corren del Líbano" (Cant 4,15); usado de manera grotesca y con una connotación sexual al rechazar a la mala mujer "Porque abismo profundo es la ramera y pozo angosto la extraña" (Prov 23,27).

El relato permite suponer que quien escucha sabe que el pozo o cisterna no sería tan profundo -seco, "vacío, sin agua", como precisa el redactorcomo para que José no escuchara los gritos y reclamos, los dimes y diretes del grupo de hermanos, tanto los decididos como los que buscaron atenuar la situación (Rubén y quizá otro) así como la negociación. José queda tirado en el hoyo, vivo, enjaulado en el trauma de la violencia de sus propios hermanos, un limbo del que no puede salir por sus propios medios y al que ha sido enviado, sin condiciones de elegir. El texto no nos dice nada sobre la situación emocional de José, los recuerdos y pensamientos que habrán pasado por su corazón, aunque varias tradiciones lo intuyen o aluden a lo que ocurre dentro: "[los] que beben vino en tazones del altar y se ungen con los óleos más finos, pero no se lamentan por la ruina de José" (Am 6,5), puesto que los pozos se usaban como cárcel "Tomando ellos a Jeremías, lo echaron en la cisterna de Malaquías...En la cisterna no había agua, sino lodo, y Jeremías se hundió en el lodo" (Jer 38,6), "Y en cuanto a ti, por la sangre de mi 
pacto contigo, he librado a tus cautivos de la cisterna en la que no hay agua (Zac 9,11), "Me has puesto en la fosa más profunda, en lugares tenebrosos, en las profundidades..." (Sal 88,6).

\section{Especias, bálsamo y mirra, sazonadas con esclavos, lujo y poder}

${ }^{25}$ Luego se sentaron a comer. Al alzar la vista, divisaron una caravana de ismaelitas que venían de Galaad, con camellos cargados de almáciga, sandáraca y ládano, que bajaban hacia Egipto. ${ }^{26}$ Entonces dijo Judá a sus hermanos: “¿Qué aprovecha el que asesinemos a nuestro hermano y luego tapemos su sangre? ${ }^{27}$ Vamos a venderlo a los ismaelitas, pero no pongamos la mano en él, porque es nuestro hermano, carne nuestra". Y sus hermanos asintieron. ${ }^{28}$ Pasaron unos madianitas mercaderes y, descubriéndolo, subieron a José del pozo. Vendieron a José por veinte piezas de plata a los ismaelitas, que se llevaron a José a Egipto.

Es chocante el relato en esas breves palabras del v. 25: "Y se sentaron (heb. yashab, de habitar, colonizar, establecerse) a comer" y aunque no se indica un tiempo, significativamente debió ser interminable para José, aunque impaciente para el grupo, puesto que se infiere en el relato que sabían que tarde o temprano pasarían las caravanas. El v. 26 nos hace sospechar que no sólo se sentaron a comer, sino a calcular precios: “Entonces dijo Judá a sus hermanos: Qué aprovecha (hebr. betsa, עְַָy, en sus acepciones de avaricia, codicia, provecho, beneficio obtenido por la violencia, lucro) el que asesinemos..." A diferencia de Rubén que cuando les sugirió a sus hermanos que echaran a José en una cisterna en lugar de matarle ahí mismo, tenía la intención de rescatar a José. Es posible que Judá tenga un motivo parecido: vender a José para que no muera en el pozo. Sin embargo, la narrativa solo menciona la posibilidad de ganancias como motivo de Judá y la espera de las caravanas.

En la segunda parte de la intervención de Judá: “...Vamos a venderlo a los ismaelitas, pero no pongamos la mano en él, porque es nuestro hermano, carne nuestra" (v. 27). Las dos partes de la propuesta de Judá revelan la tensión que sienten los hermanos. Por un lado, vender (heb. רכָ makar) a José a los Ismaelitas es tomar parte en la compraventa de esclavos. Por otro lado, vender a José a la esclavitud es menos terrible que dejarle morir en una cisterna. El hecho "que nuestro hermano es nuestra carne" aumenta esta tensión... Hasta que vieron llegar a los ismaelitas.

Ya hemos referido que el pozo estaba en el paso comercial de las caravanas. El tráfico por la ruta del creciente fértil desde Mesopotamia e incluso India, incluía todo tipo de mercancías, muchas de lujo, incluyendo esclavos, lo que daba un margen lucrativo, por lo que es significativo que José fuera vendido a una caravana de ismaelitas que llevaban especias, bálsamo y mirra a Egipto. Según la Biblia, los ismaelitas (heb. yishmeêllîm), son 
descendientes de Ismael, el hijo mayor de Abraham y de la esclava egipcia Agar. Entre las tribus nómadas descendientes del linaje de Ismael también están los nabateos, poderosos comerciantes de especias, en el norte y en el centro de la península Arábiga. Así pues, la mención de los camellos en el comercio de las caravanas y de las especies, bálsamo y mira, dado que ni la canela ni la pimienta son especias originarias de Egipto, sino que provienen de la India y de Ceilán (el actual Sri Lanka), mostraría a través de la investigación arqueológica una familiaridad obvia con los principales productos del lucrativo comercio árabe que floreció bajo la supervisión del imperio asirio en los siglos VIII-VII a.C. (FINKELSTEIN, 2001, p. 53). Las mercancías traficadas, a la vez lujosas y sagradas, debían servir tanto para las cuestiones divinas como el culto, ritos religiosos, adoración y el embalsamamiento, tanto como para las terrenales, como la cocina de las casas de la corte y los funcionarios y los cuidados de belleza.

En el camino, la provisión de esclavos semitas, tradicional y larga en muchos momentos del gobierno de las dinastías egipcias, era rutinaria, distinguiéndose a los esclavos de lujo destinados al placer, los servicios administrativos o los cuidados domésticos, vendidos a buen precio para las casas acomodadas.

Llegados a este punto, el relato nos informa que "Al volver Rubén al pozo resulta que José no estaba en él. Rasgó sus vestiduras" y luego de acordar la versión vencedora de lo ocurrido con José en el pozo y la forma de entrega de "las pruebas" al afligido Jacob, el v. 36 (de la tradición alternativa) precisa "...lo vendieron a Putifar, eunuco del faraón y capitán de los guardias". Más adelante (Gén 39,1-2) le dejarán directamente a domicilio, como una mercancía de alto valor.

\section{El largo camino de la resiliencia}

El joven soñador que es mercadeado por el tráfico internacional de esclavos hacia Egipto parece saltar muy rápidamente en el tiempo de su relato, porque de llegar a Egipto, servir en la casa de Potifar y ganar confianza a sus ojos, pasar a prisión debido a una denuncia de abuso sexual, ganar confianza nuevamente a los ojos del jefe custodio (muy probablemente el mismo Potifar), y ayudar a otros detenidos (MADRIGAL, 2007, p. 32-33), de pronto, después de haber intentado hacer incidencia con el copero para su salida de prisión, surge el recuerdo de lo vivido: "A ver si te acuerdas de mí cuando te vaya bien, y me haces el favor de hablar de mí a Faraón para que me saque de esta casa. Pues fui raptado del país de los hebreos, y por lo demás, tampoco aquí hice nada para que me metieran en el pozo" (Gén 40,1415). Tal vez José fue vendido como esclavo sexual que logró mostrar otros talentos. José identifica la prisión con el pozo del trauma. Y en un golpe de suerte de migrante, es mandado llamar por Faraón (Gén 41,14), después de una espera de unos cuantos años, al menos dos. No, no se olvida. Recuerda 
y procesa. ¿Cuánto ha costado el paso de este joven de Canaán hasta Egipto? Sin duda se ha elevado su plusvalía.

José está en el camino de cierta integración y asimilación. El acto de afeitarse, cambiarse de ropa y presentarse es todo un símbolo, de ser despojado violentamente de su túnica antes del trance del pozo y el giro que daría su vida, a vestir como egipcio. A pesar de las prisas del llamado a la corte, José toma su tiempo de preparación, indicándose con ese detalle del relato, su familiaridad con las costumbres egipcias. En contraste con la mayoría de los pueblos en el antiguo Cercano Oriente, los antiguos egipcios estaban afeitados. Al menos desde la época del Imperio Antiguo (2686-2181 a.C.), la costumbre entre los hombres era afeitarse la barba y el bigote y usar una barbilla falsa en ocasiones especiales (BLACKMAN, 1998). Los extranjeros pueden distinguirse de los egipcios nativos en muchas pinturas de tumbas egipcias por la presencia de barbas completas, por ejemplo. En un mural de la tumba de Beni Hasan, una caravana de comerciantes extranjeros barbudos trae pintura para los ojos a Egipto (c. 1890 a.C.). Al afeitarse la barba, José se transforma inmediatamente de extranjero a egipcio. Este cambio presagia la aceptación de José en la corte, así como el hecho de que más tarde los hermanos de José no lo reconocerán, tomándolo por un egipcio. Por supuesto, José se afeitó la barba y el bigote y todo el cuerpo (FRIED, 2007).

¿Por qué importa tanto la alusión a la vestimenta de José? Algunas opiniones plantean que las ropas son mencionadas en todo el ciclo porque tienen un alto contenido simbólico de filiación emocional entre hombres. En este caso, más que entre hombres, parece de alto contenido simbólico para José, es la intencionalidad de dejar de ser un migrante para ser visto, sentirse y convertirse en un siervo egipcio, un elemento integrado exitosamente en el país.

Aunque las ropas son vehículo de estatus y deseo, en este caso también lo son de eventos traumáticos y, por lo tanto, también símbolos de sanación, integración. Pero las ropas también indican mudanzas y tránsitos entre roles socioculturales, femeninos y masculinos, opresor-oprimido, según el consenso social, de la época idealmente narrada, del narrador y del público de hoy. En José opera una performance de blanqueamiento, de migrante preso a siervo favorecido.

\section{José, un dreamer}

José se convierte en un esclavo muy poderoso en Egipto ("no hay mayor en la casa [su señor] que yo" Gén 39,9). No parece ser el humilde y prudente José que nos hemos imaginado en los relatos tradicionales del "joven que venden", pero sigue siendo un cananeo, un esclavo, viviendo en Egipto. Lo cierto es que José no dice nada sobre este origen o pasado su versión más íntima no es conocida por el nuevo círculo, visto el historial con el que nos los vienen pintando: de joven diferente, violentado y vendido, a 
favorito de un eunuco y esclavo poderoso, viviendo, hablando, actuando como un integrado, a pesar de sus marcas de origen que le diferencian frente a los egipcios.

Desde esta mirada, la historia de José es un típico relato de las contradicciones y violencias sufridas y ejercidas en la construcción masculina. José se ve como un hombre que ha sobrevivido a un contexto hostil que le hace violencia y que le expulsa, obligándole a emprender un viaje donde otra vez, se tensiona entre lo que debe ser y no es. A nuestros ojos, José pasa de ser un migrante detenido en una jaula a ser un dreamer en un limbo aceptable y tolerado por la sociedad de llegada.

No es inocente o culpable de sus circunstancias, es el producto de un largo proceso de construcción por el que es transeúnte entre la sobrevivencia y la hegemonía. Por un lado, sabe tejer resiliencia de sus desgracias, es responsable por sus propios actos de violencia y tiene la capacidad de evitarlos o continuarlos, de sanarlos y asumirlos. Resulta increíble que estando en la prisión, José finalmente aluda a lo ocurrido en el pozo: "Pues fui raptado del país de los hebreos, y por lo demás, tampoco aquí hice nada para que me metieran en el pozo (bowr)" (Gén 40,15). Brota la situación traumática fundamental con la que comenzamos a ubicarle en el ciclo.

Mucho después de nuestro relato, nos llegan informes sobre José y sus hermanos, reencontrándose en Egipto: a José le ha sido dada como esposa, Azeneth la egipcia, repitiendo con ello el origen de los ismaelitas, según la tradición. Tiene dos hijos, se encuentra en un sube y baja de emociones con sus hermanos, los viste de ropajes (Gén 42-45) para que vuelvan donde su padre con la noticia que no murió en el pozo. Más tarde llegará la reunificación familiar cuando todos migren a Egipto.

Y es exactamente esa última noticia la que nos hace reconocer a un varón diferente, sobreviviente de muchas violencias, personales y sociales, intra genéricas y familiares. Un varón que desde el no-poder del fondo de un pozo y luego de la venta de su cuerpo intenta generar otros comportamientos masculinos, otros poderes, aunque algunos repitan el patrón de poder hegemónico.

\section{Menores no acompañados y al mismo tiempo, dreamers}

Es difícil sacar conclusiones cuando todavía estamos en un campo poco explorado críticamente. Hablar de las expresiones interiores, así sea reflejadas en un personaje bíblico, puede generar incomodidad, cierto miedo y ansiedad por abrir una especie de caja de Pandora, provocando rechazo, disgusto... tal vez conecte con los propios traumas. No se quiere dejar las seguridades de lo establecido y menos identificar que lo dicho por siempre tiene muchas grietas de sentido y de prácticas. Y cuando esa experiencia es vista desde las claves interseccionales y de género, no todo cae dentro de los moldes contrapuestos o complementarios dictados para hombres y mu- 
jeres. Hay más preguntas que respuestas y esto desafía una epistemología patriarcal fundada sobre respuestas y certezas.

Con relación a los niños en las jaulas, las autoridades estadounidenses siguen deteniendo a miles de niñas y niños migrantes en los centros de detención. Esto es parte de los esfuerzos de la administración para reprimir la inmigración ilegal y evitar que otros inmigrantes lleguen a la frontera de Estados Unidos. Fueron divulgados una serie de dibujos (figura 2) hechos por niños de 10 y 11 años que estuvieron en "la perrera". En ellos, los niños al medio, enjaulados, tendidos en suelo y rodeados de hombres, esperan un tiempo no cronológico sino emocional, cedidos sus derechos y potencialidades de manera temporal a manos de sus custodios.
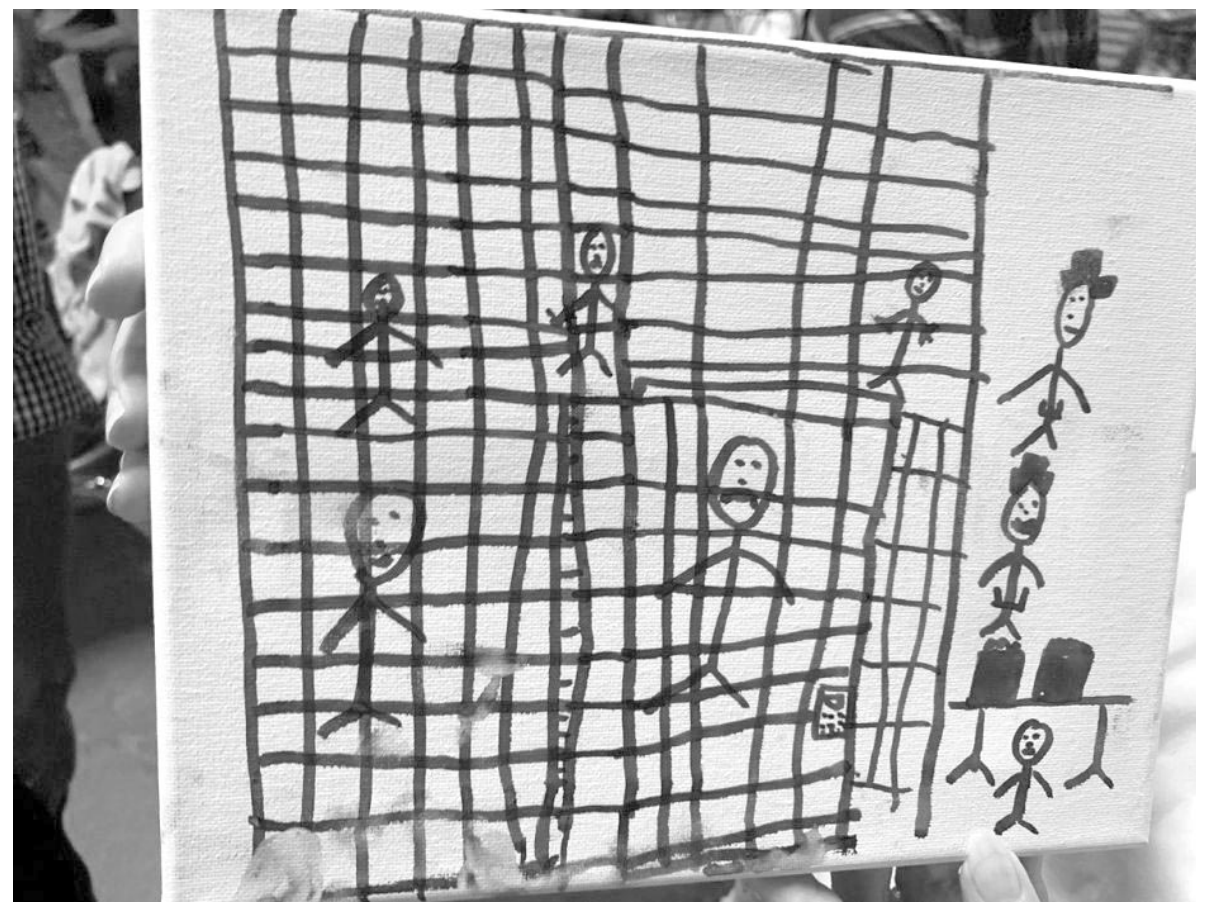

Figura 2

Dibujo de un niño migrante (2019) detenido en Texas.

En los dibujos quedó demostrado la agonía en que viven a diario. "Cuando abrí la puerta, lo primero que nos golpeó fue un olor. Era un olor a sudor, orina y heces. Y luego oí un sonido como algo que se arrugaba a mi izquierda, miré hacia allá y había mantas para calentarse y niños pequeños ... Y no tenían expresiones en sus caras. No hubo risas, ni bromas, ni charlas. Los describo casi como jaulas para perros, con personas en cada uno de ellos. Y el silencio era difícil de ver", comentaba la pediatra Dra. Sara Goza (FORTIN, 2019). 
Con José tenemos planteamientos abiertos a lectores y lectoras de hoy que se identifican con sus sufrimientos. No es posible que existan jaulas. No es tolerable, no es normal, no es anecdótico cuadro decorativo el que niños y niñas sean traumatizados. ¿Qué será de los niños y las niñas de las jaulas? Tal vez muchos regresarán a los destinos de crueldad y presión de sus lugares de origen. Otras seguirán por mucho tiempo en el limbo de las instituciones y leyes. Quizá quienes sean más resilientes logren pasar de ser "menores no acompañados", migrantes en detención provisional, a dreamers, esa otra categoría que es tolerada como inclusión, pero no real integración. Mientras tanto, muchas personas intentan denunciar la trata de personas, el negocio multimillonario de los carteles migratorios, pocas manos sacando del pozo frente a tantas manos que ponen la mano encima de los menores y reciben las monedas.

Aunque José encontró favor a la vista de Potifar y faraón, los dreamers parecen sólo encontrar sospechas y destinos como pandilleros a los ojos del señor Trump. Por dicha, al igual que José, los niños migrantes tienen el poder de resilir y soñar, a pesar del peso estructural del negocio multimillonario que les atrapó, para crecer con sus contradicciones y carencias, con sus logros y adaptaciones, sin olvidar y soñando como denuncia de espera de una vida que sea vivible y digna, así como dreamers.

\section{Referencias}

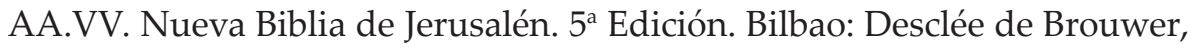
2018.

AMERICAN PSYCHOLOGICAL ASSOCIATION, APA. Resilience.

Disponible en: https://www.apa.org/topics/resilience/

Visitado el: 01 de mayo 2020.

AMERICAN ACADEMY OF PEDIATRICS, AAP. Figura 1, Dibujo de niño migrante de Texas, via Associated Press. Disponible en:

https://www.yahoo.com/news/migrant-child-drawingsdepict-jail-205825229.html Visitado el: 5 de nov. 2020.

BLACKMAN A.M. "Purification (Egyptian)," in A.B. Lloyd, ed., Gods, Priests, and Men: Studies in the Religion of Pharaonic Egypt. London: Kegan Paul International, 1998, pp. 3-21.

FINKELSTEIN, Israel y SILBERMAN, Neil Asher. The Bible Unearthed: Archaeology's New Vision of Ancient Israel and the Origin of Sacred Texts. New York: Free press, 2001. pp. 50-53.

FRAHM, Eckart. “'And His Brothers Were Jealous of Him': Surprising Parallels Between Joseph and King Esarhaddon of Assyria". Biblical Archaeology Review 42.3 (2016): pp. 43-50, 63-64.

FRIED, Lisbeth S. "Why Did Joseph Shave?" Biblical Archaeology Review 33.4 (2007): pp. 36-41. 
FORTIN, Jacey. Drawings by migrant children in Texas. Disponible en: https://www.nytimes.com/search?query=Fortin+drawings+migrants +pediatrics Visitado el: 25 de Nov. 2020.

GONZALES, R. Sexual Assault Of Detained Migrant Children Reported In The Thousands Since 2015 National Public Radio, 2019. Disponible en: https://www.npr.org/2019/02/26/698397631/sexual-assault-of-detained-migrant-children-reported-in-the-thousands-since-2015 Visitado el: 25 de nov. 2020

GUTIERREZ, GABY y SILVA, Daniella. Drawings by migrant children in detention show them in cages. NBC. Disponible en: https://www.nbcnews.com/news/latino/drawings-migrant-children-detention-showthem-cages-n1026311 Visitado el: 25 de nov. 2020.

JIMÉNEZ, Mercedes. «Como si fuera invisible» Niños, niñas y adolescentes que migran de forma autónoma en la trama fronteriza. En: EMPEZ, Núria (coord.) y AA.VV. Dejadnos crecer. Menores migrantes bajo tutela institucional. Barcelona: Virus Editorial, 2014. pp. 69-119.

MADRIGAL, Larry José. La ropa y la huida - La masculinidad íntima de José (Génesis 39, 1-23). En: AA.VV. Reimaginando las Masculinidades, Revista de Interpretación Bíblica Latinoamericana RIBLA 56, Quito, 2007/1, pp. 27-34

MUSEI VATICANI. Fotografía 1, José es vendido por sus hermanos. Mural. Raffaello Sanzio da Urbino - Raffaello Santi. Disponible en: https:// es.gallerix.ru/album/Rafael/pic/glrx-2691 visitado el 10 de oct. 2020.

SCHOICHET, Catherine. Menores cruzan solos la frontera. Disponible en: https://cnnespanol.cnn.com/2021/03/17/por-que-tantos-ninos-cruzan-la-frontera-de-ee-uu-solos/ Visitado el 21 mar. 2021.

VARJACQUES, Leah y JENSEN, Taige. Niños detenidos en la frontera. Disponible en: https://www.nytimes.com/2019/07/18/opinion/migrant-children-detention-border.html?searchResultPosition=3 Visitado el: 20 nov. 2020.

United Nations Children's Fund (UNICEF). Child migration. Disponible en: https://data.unicef.org/topic/child-migration-and-displacement/ migration/ Visitado el: 2 de abr. 2021.

Este artículo ha sido escrito gracias al apoyo de ACT Iglesia Sueca, Programa Centroamérica, como parte del proyecto "Masculinidades, género y religión. Construyendo capacidades para la corresponsabilidad de los hombres en la Justicia de género", 501490. El autor agradece los significativos aportes de realidad sobre la trata de personas de: Carmen Alegría Dávila SAC (Ecuador), Verónica Hernández, ACJ (México), Edgar Vallecillo, Cruz María Romero (El Salvador). 